\title{
FUNDAMENTAÇÃO DE UM PROGRAMA DE MUSICOTERAPIA PRÉ-NATAL
}

\author{
Eduarda Carvalho \\ Investigadora (CESEM-FCSH-NOVA-LISBOA) \\ educarte@sapo.pt
}

Fecha de Recepción: 13 Marzo 2018

Fecha de Admisión: 10 Abril 2018

\section{RESUMO}

0 uso da musicoterapia no acompanhamento da gravidez e da preparação para o nascimento constitui uma estratégia inovadora para o desenvolvimento do autoconhecimento, da expressão emocional e elaboração de sentimentos ambivalentes e da criatividade e descoberta de competências adaptativas para lidar com a mudança e transformação que o processo de gravidez e parentalidade desencadeia no casal grávido.

Partindo das bases teóricas da psicologia da gravidez e das dimensões particulares da música enquanto experiência temporal e de expressão emocional da ambivalência psicológica, será descrita uma teorização acerca dos fundamentos da musicoterapia na gravidez. Como ilustração desta teorização, serão, igualmente, descritas as linhas de orientação e de funcionamento de um programa pioneiro de musicoterapia pré-natal dirigido a casais grávidos a partir das 22 semanas de gestação.

Palavras chave: musicoterapia pré-natal; gravidez; vinculação pré-natal; preparação para o nascimento; parentalidade

\begin{abstract}
Foundation of a pre-christmas musicotherapy program.

The use of music therapy in the follow-up of pregnancy and preparation for birth is an innovative strategy for the development of self-knowledge, emotional expression and ambivalent feeling and creativity elaboration and discovery of adaptive skills to deal with the change and transformation that the process of pregnancy and parenting triggers in the pregnant couple.

Starting from the theoretical bases of pregnancy psychology and the particular dimensions of music as a temporal experience and emotional expression of psychological ambivalence, a theorization about the fundamentals of music therapy in pregnancy will be described. As an illustration of this theorization, the guidelines and operation of a pioneering prenatal music therapy program for pregnant couples from 22 weeks of gestation will also be described.
\end{abstract}

Keywords: prenatal music therapy; pregnancy; prenatal attachment; preparation for birth; parenting 


\section{CONCEITO DE MUSICOTERAPIA}

De acordo com a definição da World Federation of Music Therapy (2011), "Musicoterapia é a utilização profissional da música e dos seus elementos para a intervenção em ambientes médicos, educativos e cotidianos com indivíduos, grupos, famílias ou comunidades que procuram otimizar a sua qualidade de vida e melhorar as suas condições físicas, sociais, comunicativas, emocionais, intelectuais, espirituais, de saúde e de bem-estar. "A musicoterapia é uma disciplina especializada inspirada em diferentes modelos teóricos tais como o Modelo Humanista, Psicanalítico, CognitivoComportamental, entre outros. Distingue-se das práticas musicais com objetivos artísticos ou pedagógicos. Na prática da musicoterapia, a música não é terapêutica por si mesma, não devendo ser utilizada como um fim em si mas sim como um mediador de uma relação terapêutica individual ou em grupo orientada por um musicoterapeuta qualificado e certificado. A avaliação da identidade sonoro-musical do indivíduo constitui uma variável imprescindível na musicoterapia. Designamos por identidade sonoro-musical a forma como 0 indivíduo interiorizou a experiência sonoro-musical ao longo da sua vida, incluindo as suas memórias musicais, as preferências e rejeições musicais, bem como as atitudes e comportamentos face ao universo sonoro-musical. 0 conceito de "ISO Musical" representa a existência de um som ou de um conjunto de sons e de fenómenos acústicos/ movimentos internos que caracterizam cada indivíduo. Este conjunto de movimento/som condensa os arquétipos sonoros herdados ontogeneticamente e filogeneticamente. De forma evolutiva, associam-se-Ihe as vivências sonoro-vibratórias da vida intra-uterina e, posteriormente, as experiências sonoras vivenciadas durante e após o parto, bem como nos primeiros tempos após o nascimento da criança.

\section{OS EFEITOS TERAPÊUTICOS DA MÚSICA}

A música mobiliza o indivíduo para a ação e para a expressão emocional assim como para controlar estados de homeostasia física e psíquica. A música poderá ter efeitos de natureza fisiológica, comportamental, cognitiva, emocional e de interação social. Relativamente aos efeitos fisiológicos, a literatura aponta para impactos da musicoterapia na regulação fisiológica com benefícios na diminuição da ansiedade, na gestão do Stress e no controlo da dor. Em relação aos efeitos comportamentais, a musicoterapia poderá ter impacto na ação intencional e planeamento do comportamento motor. Relativamente aos efeitos cognitivos, a musicoterapia poderá ter benefícios no desenvolvimento das funções cognitivas da atenção, memória e estruturação de sequências lógicas ou narrativas. Em relação aos efeitos emocionais da música, a prática da musicoterapia aponta para impactos na expressão e regulação das emoções e na recuperação de memórias a longo prazo ou memórias recalcadas por experiências traumáticas anteriores à aquisição da linguagem falada. No que respeita aos efeitos sociais da música, a musicoterapia individual aponta para benefícios na aquisição de capacidades de reciprocidade, sincronização e harmonização com benefícios no desenvolvimento da interação, da intencionalidade comunicativa e na prática da musicoterapia em grupo sugerindo benefícios na cooperação interpessoal e na aquisição de sentimentos de pertença e de coesão grupal. 0 recurso à musicoterapia, através da presença do fluxo sonoro-musical, permite a continuidade da interação e da comunicação, mesmo na ausência de palavras ou perante à dificuldade na elaboração simbólica do pensamento em casos de maior fragilidade ou regressão do Self. É na área do desenvolvimento e reestruturação do Self que a musicoterapia parece revelar benefícios, comparativamente a outras modalidades de psicoterapia verbal, sobretudo em casos onde a linguagem falada poderá estar comprometida ou inibida por fatores emocionais ou em casos onde a ambivalência psicológica dificulta a subjetivação e a verbalização da expressão emocional. Comparativamente a outras modalidades de psicoterapia verbal, a musicoterapia tem como vantagem permitir 0 acesso a memórias afetivas associadas a acontecimentos e episódios do ambiente 
primordial da infância em períodos anteriores à ocorrência da linguagem verbal e do pensamento simbólico.

\section{A GRAVIDEZ COMO PROCESSO DE ELABORAÇÃO PSICOLÓGICA}

A gravidez constitui para a mulher um período de crise psicológica e de reestruturação identitária que exige um ajustamento psicológico na regulação das emoções e harmonização de estados emocionais relativamente a si mesma e ao bebé. Segundo o modelo de Colman e Colman (1971) poderemos teorizar a elaboração psicológica da gravidez através de três etapas elaboradas de forma sucessiva em cada um dos três trimestres de gestação. No primeiro trimestre, desenvolve-se a "etapa da incorporação" caracterizada por uma vivência de maior ambivalência e de elaboração da aceitação da gravidez, havendo a necessidade de reavaliar aspetos relacionados com as relações objetais primárias. No segundo trimestre, desenvolve-se a "etapa da diferenciação" caracterizada pelo aparecimento das primeiras representações acerca do bebé imaginário, facilitada pelo início da perceção dos movimentos fetais. Finalmente, no terceiro trimestre, surge a "etapa da separação" caracterizada pela preparação para o nascimento e transição para a parentalidade através de uma reavaliação e reestruturação do relacionamento conjugal assim como a projeção de cenários futuros na constituição de uma nova família. Ao aproximar-se o nascimento, o futuro bebé real, mais do que 0 bebé imaginário, começa a ocupar o pensamento materno. No final da gravidez, surge um estado de "preocupação maternal primária" (Winnicott, 1956) através do qual, a futura mãe começa a desenvolver a capacidade empática de se colocar no lugar do bebé, construindo-o de forma mais realista.

\section{FUNDAMENTAÇÃO DA MUSICOTERAPIA PRÉ-NATAL}

Três dimensões particulares da música estão na base dos seus fundamentos de ação terapêutica do domínio da elaboração psicológica da gravidez e preparação para o nascimento: 1- a expressão da ambiguidade, 2- a abertura à flexibilidade e 3- a experiência temporal. A primeira dimensão particular da música é o facto de ela permitir a "expressão da ambiguidade" pela justaposição de sentimentos opostos possibilitando a expressão e a integração de sentimentos ambivalentes, particularmente presentes durante a gravidez. Na prática da musicoterapia pré-natal, a proposta de criação de canções parentais para o bebé que vai nascer poderá constituir uma estratégia eficaz e prazerosa na expressão e elaboração de sentimentos contraditórios dirigidos ao bebé ou à própria grávida, permitindo assim a integração de sentimentos de ambivalência. Estes que dificilmente podem ser verbalizados, no entanto podem ser cantados e, por isso, elaborados esteticamente a partir de uma canção parental original. A segunda dimensão da música é a de permitir uma experiência de flexibilidade, variação, improvisação e criatividade, aspetos estes igualmente importantes no processo de parentalidade permitindo o ensaio para a mulher grávida e o casal grávido se flexibilizarem face à imprevisibilidade e incerteza, presentes no processo de parentalidade. As técnicas de improvisação musical em musicoterapia têm demonstrado impacto na saúde (MacDonald, et al. 2014). A sua aplicação no domínio da elaboração da ambivalência na gravidez permite explorar musicalmente a incerteza permitindo expressar musicalmente a imprevisibilidade através de uma produção musical estética de "rêverie musical". Relativamente à terceira dimensão, a dimensão temporal da música, podemos focar a nossa ação e o pensamento no instante presente ou na evocação de memórias passadas ou ainda na antecipação de cenários futuros. A vivência temporal está tão presente na música como na elaboração psicológica da gravidez, ora canalizando a mulher grávida para a reactualização de experiências infantis no reencontro com o objeto materno primário, ora focando a mulher grávida numa vivência atual do encontro com o seu bebé imaginário, ora ainda antecipando o seu pensamento no futuro próximo pela evocação de cenários de representação de si 


\section{FUNDAMENTAÇÃO DE UM PROGRAMA DE MUSICOTERAPIA PRÉ-NATAL}

mesma como mãe, do seu parceiro como pai e do seu futuro bebé no seio da sua família imaginária. A experiência temporal do primeiro trimestre é mais canalizada para a evocação do passado em virtude da "transparência psíquica" da gravidez (Bydlowski, 2001) caracterizada por uma experiência de regressão do Self, associada à reminiscência de conteúdos de vivências do passado. Deste modo, poderemos fundamentar o contributo da musicoterapia na elaboração de memórias infantis e na recriação da história infantil da mãe através de lembranças sonoras e musicais no contacto com o objeto materno primário (recordação e recriação das canções de embalar da mulher grávida no encontro com o seu objeto materno primário). Por ocasião do segundo trimestre, 0 aparecimento da perceção dos movimentos fetais conduz a grávida a uma experiência temporal focada no presente através da escuta empática das reações do bebé à estimulação sensorial, incluindo 0 ambiente sonoro. É a partir do segundo trimestre e, sobretudo, a partir das primeiras perceções dos movimentos fetais que poderemos fundamentar o uso da musicoterapia no sentido de promover a sensibilidade empática do casal grávido para a leitura atenta dos sinais emitidos corporalmente pelo feto em reação aos estímulos sensoriais e, em particular, à voz, ao canto parental e à música escutada pelo casal. Esta leitura constitui uma forma de ensaiar a capacidade intuitiva, empática e de "rêverie" da mãe e do pai para se sintonizarem com o bebé, preparando-se para entrar em sintonia e sincronia com a criança após o nascimento. Para além de um ensaio de trocas sensoriais com 0 feto através da música, a presença empática da música permitirá a criação de um clima afetivo propício ao processo da vinculação pré-natal. No terceiro trimestre a vivência temporal é canalizada para a preparação do nascimento e para a antecipação de cenários futuros onde a grávida se imagina como mãe imaginando também o seu bebé que vai nascer e que ocupará um espaço real no seio da família.

\section{APLICAÇÕES DA MUSICOTERAPIA: OBSERVACC̃̃ES EMPÍRICAS}

No domínio da aplicação dos efeitos terapêuticos da música, poderemos fundamentar os efeitos fisiológicos, psicológicos e sociais da música no acompanhamento da gravidez e no parto. Os efeitos fisiológicos da música na gravidez (Chang, Chen, Huang, 2008) têm a finalidade de obter benefícios na regulação emocional, na diminuição da ansiedade e na regulação do Stress para além da libertação de oxitocina catalisadora do trabalho de parto e da vinculação neonatal. Os efeitos psicológicos da música na gravidez estão associados à função de expressão emocional e evocação musical de memórias infantis, bem como a expressão e integração de sentimentos de ambivalência afetiva, dificilmente expressos verbalmente. Os efeitos sociais são também fundamentados através da abertura de canais de comunicação sonora catalisadores da escuta empática em relação à própria grávida, ao seu bebé, ao parceiro conjugal/parental e à rede social envolvente composta pelos membros do grupo (grávidas ou casais grávidos) que partilham mutuamente experiências comuns de elaboração e ajustamento do Self no seio da dinâmica de grupo.

\section{A MUSICOTERAPIA NA PREPARAÇÃO dO PARTO E NO CONTROLO DA ANSIEDADE}

Os benefícios da musicoterapia com mulheres grávidas tem sido documentada em várias investigações desde os anos oitenta (Clark, McCorkle \& Williams, 1981; McKinney, , 1990). As primeiras intervenções terapêuticas da música em obstetrícia visavam o controlo da dor no trabalho de parto através da promoção de associações positivas durante o trabalho de parto. Os estudos pioneiros da aplicação da escuta musical no trabalho de parto tinham como objetivos: a) a focalização da atenção, através da escuta musical ativa, como estratégia eficaz de dissimular a dor; b) a regulação dos padrões respiratórios, sincronizados com o ritmo musical, de acordo com a fase do trabalho de parto e c) a promoção do relaxamento com o acompanhamento musical (McKinney, 1990). Clark, McCorkle e Williams (1981) foram os primeiros autores a descrever um programa de intervenção 
da musicoterapia na preparação do parto ajustando o ritmo e a intensidade musical ao estádio dois do trabalho de parto. As puérperas oriundas do grupo experimental relataram sentimentos positivos nas suas vivências do parto, comparativamente ao grupo de controlo. Hanser, Larson e 0' Connell (1983) ajustaram o ritmo musical ao ritmo dos padrões respiratórios do sujeito. Verificaram que os sujeitos testados demonstravam menos respostas de dor enquanto a música acompanhava e sincronizava a respiração, comparativamente aos períodos alternados sem 0 acompanhamento musical. Winoker et al. (1984) também treinaram grávidas ajustando a música ao ritmo respiratório e foi observado um maior relaxamento e uma diminuição da duração do trabalho de parto com menor uso de medicamentos em mulheres que tinham sido acompanhadas com programas de musicoterapia durante 0 trabalho de parto. Algumas pesquisas verificaram um impacto da musicoterapia na redução dos estados de ansiedade no parto (Liu et al, 2010) e outras observaram benefícios da musicoterapia como estratégia de copping na preparação para uma cesariana (Kushnir, et al. 2012). Apesar de a literatura referir como critérios de seleção musical no parto, dimensões que se relacionam com escolhas dos sujeitos participantes ou dimensões intrínsecas da música associadas a parâmetros fisiológicos (ritmo respiratório) importa clarificar cientificamente quais os critérios que se revelam mais adequados na escolha do reportório musical nos programas de escuta musical.

\section{A MUSICOTERAPIA NA ELABORAÇÃO PSICOLÓGICA DA GRAVIDEZ}

Parece existir uma correlação positiva entre as variáveis psicológicas e as variáveis físicas na gravidez. Partindo deste pressuposto, observa-se que a manutenção da homeostasia física está relacionada com a promoção de fatores de equilíbrio emocional na gravidez. Com base nestas observações, alguns musicoterapeutas (Chang, Chen, Huang, 2008; Sidorenko, V. N., 2000) dirigem a sua intervenção para facilitar a expressão de sentimentos associados à reestruturação identitária e elaboração psicológica da gravidez. 0 musicoterapeuta argentino Gabriel Federico $(2001,2003)$ desenvolveu um Programa de Musicoterapia Pré-natal (Método "Mamisounds", 2001) composto por várias técnicas recetivas e ativas de musicoterapia, entre as quais a "Técnica RAM" ("relaxamento através do movimento"), a técnica de "visualização criativa com música", a técnica do "banho sonoro" e a técnica das "canções de boas vindas" criadas pelos futuros pais para o bebé que vai nascer (Federico, 2001, 2003). "A utilização da visualização criativa com música, na gravidez, permite a conexão com o tempo presente e, igualmente, a evocação do passado e a projeção do tempo futuro" (Federico, 2003), proporcionando uma experiência de temporalidade que nos parece inerente e benéfica à elaboração psicológica da gravidez. Como afirma Federico (2003), as visualizações guiadas com a música devem ser dirigidas a aspetos emocionais particulares de cada grávida. A elaboração destas fantasias maternas que surgem sob a forma de imagens mentais é realizada no seio do grupo na sequência da escuta musical através da discussão verbal, discutindo-se o seu significado latente.

\section{A MUSICOTERAPIA NA PROMOÇÃO DA VINCULAÇÃO MATERNO-FETAL}

A função empática é uma das funções primordiais da utilização da música em musicoterapia sob a qual assenta o princípio primordial de ISO. Baseada nesta função empática e de ressonância emocional, observa-se, como outro dos efeitos da música na gravidez, promover e desenvolver os laços de vinculação pré-natal da mãe e do pai com o bebé antes de nascer, verificando-se que 0 estabelecimento desses laços antes do nascimento é preditivo de uma adequada vinculação precoce na relação primária. É comum constatar-se a existência de grávidas que recorrem à música para tentarem diminuir a ansiedade na gravidez ou simplesmente para adquirirem experiências de bem-estar e de comunicarem com 0 seu bebé. Os estudos de musicoterapia dirigidos à promoção da vinculação com o bebé dão primazia à experiência de contacto com a voz materna (Carolan, M. et al. 2011). 


\section{FUNDAMENTAÇÃO DE UM PROGRAMA DE MUSICOTERAPIA PRÉ-NATAL}

As canções dirigidas ao bebé antes de nascer marcam uma das técnicas privilegiadas a esse nível. As canções acompanham-nos desde o início da nossa existência, marcando a nossa história de vida. São também património herdado de forma transgeracional, favorecendo um sentimento de pertença identitária e cultural, evocando a memória de um Povo, Raça ou Nação. As canções de embalar constituem as primeiras canções que fazem parte da memória do indivíduo, transmitidas e transformadas de forma transgeracional entre avós, pais e filhos, ao longo da sua evolução ontogenética. 0 uso das técnicas vocais e de construção de canções constitui uma das principais metodologias da musicoterapia no âmbito da gravidez e da perinatalidade. São muitos os programas de musicoterapia (Carolan, M., et. 2011), onde os musicoterapeutas sugerem e incentivam os futuros pais a criarem canções para o bebé que vai nascer, ajudando-os à criação do bebé imaginário e a promover os primeiros vínculos com o bebé. Cremos que estas canções contêm, em si mesmas, 0 património da proto-identidade da criança antes de nascer, tal como emerge no imaginário dos seus pais. 0 musicoterapeuta Gabriel Federico (2005) inclui, no seu programa de "musicoterapia focal obstétrica", entre outros procedimentos técnicos, a técnica vocal. Entre as técnicas vocais, o autor dá primazia às "canções de boas vindas" criadas pelos futuros pais, para o bebé que vai nascer com a finalidade de promover os vínculos.

\section{PROGRAMA DE MUSICOTERAPIA PRÉ-NATAL NA PREPARAÇÃO PARA O NASCIMENTO}

Na sequência da fundamentação teórica, serão descritas as linhas de orientação de um programa de musicoterapia pré-natal na preparação para 0 nascimento e para a parentalidade que foi implementado em 2005 no Espaço da Saúde da Criança e do Adolescente (ESCA), uma Clínica Privada composta por uma equipa multidisciplinar prestadora de cuidados de saúde dirigidos à infância, à adolescência e à parentalidade. Os princípios orientadores de este programa tinham como preocupação: 1- a intervenção multidisciplinar no acompanhamento da gravidez e na preparação para o nascimento oferecendo igual relevo à dimensão física e à dimensão psicológica; 2- a participação ativa e criativa do casal grávido; 3- a prevenção e intervenção precoce no acompanhamento da gravidez e da promoção da vinculação pré-natal; 4- a preparação para uma vivência positiva do parto e nascimento com participação ativa do casal mediante o recurso à escuta musical ou às vocalizações no trabalho de parto; 5- a promoção da dinâmica de grupo com recurso a técnicas da musicoterapia integrada com outras expressões artísticas tais como a expressão corporal, a expressão pictórica e a escrita criativa de canções dirigidas ao bebé antes de nascer. A metodologia de orientação semi-diretiva privilegiava a livre expressão de ideias, dúvidas e sentimentos em torno das representações da gravidez e da parentalidade. Os sentimentos de ambivalência que por vezes são difíceis de expressar verbalmente eram metabolizados através de propostas expressivas e criativas com recurso à improvisação musical e comunicação sonora no grupo. 0 programa era composto por oito sessões com periodicidade semanal ou quinzenal, conforme a idade gestacional da grávida no início da intervenção. Antes do início das sessões de musicoterapia em grupo, era realizado uma entrevista clínica com cada casal grávido com o objetivo de recolher informação importante não apenas acerca da história clínica e obstétrica mas igualmente para recolher aspeto relacionados com a história sonoro-musical do casal (preferências musicais, hábitos musicais, recordações musicais, as reações do bebé à estimulação sonora e musical e os modos preferenciais de interação sensorial com ele, etc). As várias propostas expressivas e criativas no seio da dinâmica de grupo associavam-se a aspetos temáticos relacionados com a elaboração psicológica da gravidez, vinculação pré-natal, preparação para o parto e nascimento. Como poderemos observar na Tabela 1 , as sessões eram orientadas para a expressão e elaboração de conteúdos temáticos vivenciados a partir de propostas musicais tais como a revisão das vivências musicais da infância de cada progenitor, as recordações das músicas do casal grávido, a interação com o bebé através da música, a 
proposta de uma canção parental dirigida ao bebé, a preparação musical para o parto e a preparação do enxoval musical dirigido às interações com o bebé após o nascimento. A proposta da recriação do "retrato rítmico do bebé imaginário" a partir da perceção dos movimentos fetais constituía uma estratégia inovadora na criação da pré-subjectivação do bebé antes de nascer, permitindo a atribuição de uma proto-identidade. Relativamente às técnicas recetivas da musicoterapia, as propostas de escuta musical eram sobretudo focadas na escuta das músicas da história de cada casal, na seleção de músicas para servirem de foco de atenção durante o trabalho de parto e, ainda, na recoIha de músicas de cada casal para acompanharem os primeiros tempos de vida após o nascimento. Em relação às técnicas ativas da musicoterapia, eram propostas experiências de comunicação dialógica e sonora de cada casal, a composição de uma canção original para o bebé e, ainda, a proposta de comunicação sonora em grupo pela improvisação musical capacitando o grupo para lidar com situações de imprevisibilidade de forma estética e criativa. 0 desenvolvimento do processo criativo no contexto da comunicação sonora do grupo constituía uma estratégia eficaz para o autoconhecimento e para a tomada de consciência dos recursos do Self mediante a exploração e descoberta de competências adaptativas para lidar com a mudança, transformação, imprevisibilidade e antecipação que o processo de gravidez e parentalidade desencadeia na mulher grávida e no casal grávido.

\section{BIBLIOGRAFIA}

Bydlowski, M. (2001). "Le regard intérieur de la femme enceinte, transparence psychique et représentation de l'object interne", Devenir, Vol. 13, $n^{\circ}$ 2, 41

Clark, M. E., McCorkle, R. R., \& Williams, S. (1981). Music therapy assisted labour and delivery. Joumal of Music Therapy, 18(2).

Clark, McCorkle \& Williams (1986). Music Therapy Assisted Childbirth: A Practical Guide. Music Therapy Perspectives, 3.

Carolan, M., Barry, M., Gamble, M., Turner, K., Mascarenas, 0., (2011). The Limerick Lullaby project: an intervention to relieve prenatal stress. Midwifery 10.1016/ j.midw.2010.12.006.

Chang, M.Y., Chen, C.H., Huang, K.F., (2008). Effects of music therapy on psychological health of women during pregnancy. Journal of Clinical Nursing 17, 2580-2587.

Chang, S.C., Chen, C.H., (2005). Effects of music therapy on women's physiologic measures, anxiety, and satisfaction during cesarean delivery. Research in Nursing and Health 28, 453-461.

Colman, A., \& Colman, L. (1971). Pregnancy: the psychological experience. New York: Herder \& Herder, Inc.

Federico, G. F. (2001). El embarazo musical. Editorial Kier S. A. Buenos Aires. Argentina.

Federico, G. F. (2003). Melodias para el bebé antes de nascer. Editorial Kier S. A. Buenos Aires. Argentina.

Federico, G. (2005). Musicoterapia focal obstéctrica, XI Congreso Mundial

de Musicoterapia, Brisbane, Australia.

Hanser, S., Larson, S., \& O'Connell, A. (1983). The effect of music on relaxation of expectant mothers during labour. Iournal of Music Therapy, xx(2), 50-58.

Kushnir, J.; Friedman, A.; Ehrenfeld,M. \& Kushnir, T. (2012). Coping with preoperative Anxiety in Cesarean: Section Physiological, Cognitive, and Emotional Effects of Listening to Favorite Music BIRTH 39:2.

Liu, Y-H; Chang, M-H \& Chen,C-H. (2010). Effects of music therapy on labour pain and anxiety in Taiwanese first-time mothers, Journal of Clinical Nursing, 19, 1065-1072.

Mckinney, Cathy, H. (1990). Music Therapy in Obstetrics: A Review. Music Therapy Perspectives, vol.8. 


\section{FUNDAMENTAÇÃO DE UM PROGRAMA DE MUSICOTERAPIA PRÉ-NATAL}

MacDonald, R. A., and Wilson, G. B. (2014). Musical improvisation and health: a review. Psychol. Well Being 4, 1-18.

Sidorenko, V. N. (2000). Clinical application of medical resonance therapy music in high-risk pregnancies. Integrative Physiological \& Behavioral Science, 35, 199-207.

Winnicott, D. W. (1956). "A preocupação Maternal Primária" (2000) In Da Pediatria à Psicanálise. Lisboa: Imago Editora.

Winoker, M. A. (1984). The use of music as an audio-analgesia during childbirth. The Florida State University.

Tabela 1. Conteúdos temáticos e propostas expressivas nas sessões de grupo

\begin{tabular}{|c|c|c|}
\hline História do casal & $\begin{array}{l}\text { Recolha de musicas } \\
\text { acerca da história de } \\
\text { cada casal para escutar } \\
\text { em grupo seguida de } \\
\text { partilha verbal de } \\
\text { evocações. }\end{array}$ & $\begin{array}{l}\text { Tomada de consciência } \\
\text { da dinâmica de relação } \\
\text { e comunicação de cada } \\
\text { casal, escuta do casal e } \\
\text { tipo de comunicação do } \\
\text { casal. }\end{array}$ \\
\hline História de Infância dos pais & $\begin{array}{l}\text { Recolha e recriação de } \\
\text { canções do reportório } \\
\text { musical da infância }\end{array}$ & $\begin{array}{l}\text { Atualização de } \\
\text { memórias de infância e } \\
\text { tomada de consciência } \\
\text { das relações parentais. }\end{array}$ \\
\hline Sentimentos de ambivalência & $\begin{array}{l}\text { Improvisação musical } \\
\text { em torno de } \\
\text { sentimentos opostos. }\end{array}$ & $\begin{array}{l}\text { Expressão, elaboração } \\
\text { e integração de } \\
\text { sentimentos de } \\
\text { ambivalência difíceis } \\
\text { de serem verbalizados. }\end{array}$ \\
\hline $\begin{array}{l}\text { Representação } \\
\text { do bebé imaginário }\end{array}$ & $\begin{array}{l}\text { Construção de } \text { uma } \\
\text { canção para o bebé } \\
\text { antes de nascer. }\end{array}$ & $\begin{array}{l}\text { Promoção da } \\
\text { vinculação pré-natal }\end{array}$ \\
\hline Preparação para o parto & $\begin{array}{lr}\text { Orientação da } & \text { seleção } \\
\text { musical para o parto e } \\
\text { exercícios } & \text { de } \\
\text { vocalização. } & \end{array}$ & $\begin{array}{l}\text { Promoção de uma } \\
\text { vivência positiva e } \\
\text { estética do parto com } \\
\text { participação criativa do } \\
\text { casal gravido }\end{array}$ \\
\hline Preparação do nascimento & $\begin{array}{l}\text { Construção do } \\
\text { "enxoval musical" } \\
\text { composto por canções } \\
\text { de embalar e seleção de } \\
\text { musicas do casal para } \\
\text { escutar no final da } \\
\text { gravidez e após o parto. }\end{array}$ & $\begin{array}{lr}\text { Promoção } & \text { do } \\
\text { ajustamento materno } \\
\text { na transição da } \\
\text { gravidez para a } \\
\text { maternidade } \\
\text { recurso a reportório } \\
\text { musical facilitador de } \\
\text { harmonização de } \\
\text { estados de regulação } \\
\text { emocional, promoção } \\
\text { da vinculação neonatal } \\
\text { e acompanhamento na } \\
\text { amamentação. }\end{array}$ \\
\hline
\end{tabular}

